\title{
THE IMPACT OF LECTURERS' THINKING STYLES ON STUDENTS' CREATIVITY IN DISTANCE HIGHER EDUCATION
}

\author{
Dr. Mohammad Reza SARMADI \\ Faculty of Human Sciences \\ Payame Noor University, Iran \\ Dr. Mehran FARAJOLLAHI \\ Faculty of Human Sciences \\ Payame Noor University, Iran \\ Dr. Bahman SAEIDIPOUR \\ Faculty of Human Sciences \\ Payame Noor University, Iran \\ Dr. Mehrdad AHMADIFAR \\ Faculty of Human Sciences \\ Payame Noor University, Iran
}

\section{ABSTRACT}

The purpose of this study was to investigate the group creativity on thinking styles in distance education based on collaborative learning. Sample included 120 students from three intact classes of the College of education were selected as the participants for the main study. The instruments of measurement were the thinking styles inventory and the creative product semantic scale. Using the factorial quasi-experimental design, impact of thinking styles in the group creativity was tested. The results of the present study showed that male students tended to prefer the legislative thinking style more than the female students. There was no significant difference between male and female students in the overall creative ability. In addition, this study found that there was no significant association between the average group member creative ability and the overall group creative performance. The findings also supported Sternberg's argument that ability is different from style.

Keywords: Thinking styles, distance learning, group creativity.

\section{INTRODUCTION}

Online collaborative learning environments have the potential to support teaching and learning relying on social interaction between group members (Kreijns et al., 2004). The best way of grouping lies in each single group containing students with different thinking styles, which bring forth better cooperative results. Teachers should create a learning environment in which students with different thinking styles can capitalize on their strengths and compensate for their weaknesses of thinking and learning, therefore proposed the theory of mental self-government to assist teachers to enhance the effectiveness of teaching and learning (Sternberg, 1990).

Thinking styles are among the major resources that give rise to creativity. A number of research studies have supported meaningful relationships between certain thinking styles and creativity (Yang \& Lin, 2004). It is widely believed that the development of creativity is influential to the success of an organization. Empirical findings reveal that some styles of thinking have significant correlation with creative thinking. Scholars have recognized 
that creative thinking is valuable for both individuals and society (Sternberg, 1997; Yang \& Lin, 2004). Sofo(2008) characterizes thinking styles as the most comfortable ways of individuals responding to a situation, that lead to specific habitual styles that influence people's cognition and emotion which guide and control people's daily activities. Thinking style refers to the specific approach of individuals in processing and evaluating information, solving problems, and making decisions (Armstrong \& Cools, 2009). Style of thinking is unique and adaptive. It has a different domain from other individual traits, such as personality, emotional intelligence and abilities (Fjell \& Walhovd, 2004; Haller \& Courvoisier, 2010; Murphy \& Janeke, 2009; Zhang, 2010). The literature indicate that thinking styles link personality and cognition (Sujan, 1995). Moreover, style of thinking is identified as socialized, which means that thinking styles can be affected by intellectual, emotion, motivation, physical and mental well-being, and environment (Sofo, 2008; Zhang \& Sternberg, 2006). Thinking styles may influence all human activities that involve learning, social and interpersonal functioning. (Zhang, 2003). Thinking style is partially developed through socialization and often operate unconsciously, therefore leading individuals to perceive a given situation variously (de St. Aubin, Blahnik, \& Lucas, 2007). People may accommodate their styles through interaction with their surroundings; hence, the environment is one fundamental aspect that may influence a person's preference of styles (Sternberg, 1997; Zhang \& Sternberg, 2005). In work settings, environment can influence people's thinking styles, therefore people who work in a more favorable environment are generally happier, thus more willing to take risks, to be innovative and to be persistent in trying different ways of solving problems. They tend to think more creatively and use a wider range of thinking styles (Zhang, 2005). Sternberg expanded the concept of thinking styles upon mental self-government theory; He used this theory to explain the thinking characteristics of creators. He divided thinking styles into 5 main categories and 13 detailed types (Sternberg, 1988; 1990; 1997). Table 1 shows main categories and detailed types of thinking styles.

Table: 1

Five main categories and 13 detailed categories of thinking styles.

\begin{tabular}{|c|c|}
\hline Main categories & Detailed types \\
\hline Functions of mental self-government & $\begin{array}{l}\text { 1. Executive } \\
\text { 2. Legislative } \\
\text { 3. Judicial }\end{array}$ \\
\hline Forms of mental self-government & $\begin{array}{l}\text { 1. Monarchic } \\
\text { 2. Hierarchic } \\
\text { 3. Oligarchic } \\
\text { 4. Anarchic }\end{array}$ \\
\hline Levels of mental self-government & $\begin{array}{l}\text { 1. Global } \\
\text { 2. Local }\end{array}$ \\
\hline Orientations of mental self-government & $\begin{array}{l}\text { 1. Internal } \\
\text { 2. External }\end{array}$ \\
\hline Ideologies of mental self-government & $\begin{array}{l}\text { 1. Liberal } \\
\text { 2. Conservative }\end{array}$ \\
\hline
\end{tabular}

In the field of education, scholars identified that thinking styles contribute significantly to students' academic achievement, learning approaches, cognitive development and social development (Bernardo, Zhang, \& Callueng, 2002). Thinking styles also affect teaching behaviors, such as teaching approaches and interaction styles. (Zhang, 2011; Zhang \& Sternberg, 2002). Teachers' thinking styles characterize interpersonal behavior towards students, whether they are helping, understanding and allowing student freedom, or they are being strict, showing dissatisfaction and expressing anger. Thinking styles are among the major resources that give rise to creativity. A number of research studies have supported meaningful relationships between certain thinking styles and creativity (Yang \& Lin, 2004). It is widely believed that the development of creativity is influential to the success of an organization. Empirical findings reveal that some styles of thinking have 
significant correlation with creative thinking. Scholars have recognized that creative thinking is valuable for both individuals and society (Sternberg, 1997; Yang \& Lin, 2004).

Sternberg also contended that although someone might have creative ability, they may not enjoy coming up with novel ideals challenging prevailing view points (Sternberg \& Lubart, 1995). Conversely, that while someone might not be creative, they may prefer generating unorthodox ideas (Sternberg \& Zhang, 2005). Creativity is the capacity to produce ideas under an observable form or to realize a production that is both novel, i.e. original and unexpected, and adapted to the situation in which it occurs (Bonnardel, 2006; Bonnardel, 2009; Bonnardel and Zenasni, 2010). Most creative acts occur in a collaborative context (Sonnenburg, 2004). For example, groups provide a sufficient pool of knowledge, experiences, and views to produce an optimal outcome at each stage of the problem- solving process (Lohman \& Finkelstein, 2000).

In recent years, there has been increasing acknowledgment of a more complex view of creativity, highlighting the role of dynamic and interconnected social systems, such as mentoring an collaboration, in creative work. Some group researchers claim that by providing many different perspectives for consideration, diversity within a group can help the creative process and promote more innovative outcomes (Kurtzberg \& Amabile, 2001; Kurtzberg, 2005; Mamykina et al., 2002). Empirical studies show that the impact of diversity on group performance may not be as positive as many would like to believe (Williams \& O'Reilly, 1998). Sometimes, heterogeneity in group composition even decreases the initial degree of satisfaction of group members, and some researchers (Milliken et al., 2003; Nemeth \& Nemeth-Brown, 2003) indicate that perceived individual differences among group members may have negative effects on both emotional reactions (e.g. group identification, emotional conflict, psychological safety, and group satisfaction) and cognitive processes (e.g. thinking differently about an issue), and may make it difficult for individuals to identify themselves as belonging to the group. Therefore, in the early formative phases of group interaction, differences can induce conflict and frustration among members, and this can carry over subsequent operational and performance phases (Paulus \& Nijstad, 2003). "Diversity, thus, appears to be a double-edged sword that increases the opportunity for creativity as well as the likelihood that group members will be dissatisfied and fail to identify with the group" (Milliken \& Martins, 1996, p.403). Milliken et al. (2003) believed that an important moderator of the relationship between diversity and a work group's affective reactions is the perception of a super ordinate goal. When members perceive they are working toward a common goal, the negative effects of diversity on a group's initial affective reactions may be attenuated. A critical factor promoting the perceptions of a super ordinate goal is the structure of a work group's task and reward system (Tjosvold, 1986). Tjosvold (1988) noted that a cooperative orientation, with the exchange of resources and information, and openness to each other's ideas, could be induced by creating a common task requiring group collaboration. Wageman (1995) also found that a group task that has a high-level task interdependence leads to a greater sense of collective responsibility.

Milliken et al. (2003) stated seem to play a critical role in a group's activities. Hinsz et al., (1997) also noted that group members' affective reactions affect how groups approach their tasks. Milliken et al. (2003) indicated that members who identify more strongly with the group would tend to be more willing to contribute to the collaborative product. In addition, group members with substantial psychological safety are more likely to feel positive about the group and its task. In contrast, group members with low psychological safety generally feel disinterested in the group and are less like to engage with it. Moreover, negative moods are associated with a high level of emotional conflict and low levels of group satisfaction, and such conflict may lead to narrow and rigid thinking, thus reducing creativity. In contrast, a positive mood may enhance participation and increase members' capacity to generate unusual and creative ideas. An additional factor that may reduce group performance is conformity, the desire for social consensus, which induces agreement without reflection and limits the ability of individuals' to think in alternative ways (Nemeth \& Nemeth-Brown, 2003). Due to fear of social sanctions or the assumption that the majority is probably correct, people in groups often agree, and this conformity harms creativity. 
Woo, Lee \& Kim (2009) suggested that cooperative learning depends on not only group members' capability, but also quantity and quality of interaction. Therefore, appropriate team composition strategies are necessary to enhance creativity within the group. Many researchers have a tentative conclusion that heterogeneous group composition is more effective than homogeneous group composition (Sawyer, 2007). In addition, group creativity is optimized when group members have different perspectives (Nemeth \& Kwan, 1985). There are reports that discordance between team members thinking increases probability of finding novel and appropriate solutions (Nemeth et al., 2004). However, Woo (2010) warned extreme diversity is harmful to group creativity. Based on his finding, Woo (2010) recommend that group composition through cognitive diversity is one of the most effective methods. Also, Kim (2007) suggested that different working styles maximize synergy among group members. In conclusion, heterogeneous group composition creates a complementary relationship among group members so that group creativity is maximized. However, agreed specific strategies are still absent. Through empirical data, this paper aims to discover specific strategies that lead to a significant improvement in students' group creativity. We are considering students thinking styles as the parameter of group creativity, and the affect of thinking styles during learning in distance education.

\section{RESEARCH METHODOLOGY}

The aim of this study was to investigate the students' group creativity on thinking styles in distance education based on collaborative learning. The target population for this work was full-time university students in Iran. Students from the Payame Noor University, which is located in the Western part of Iran, served as the non-random convenience sample in this study. Thirty-second year students from three intact classes of the College of Education were selected as the participants for the study.120 student from virtual courses took part in the research.

Because the researcher was interested in making comparisons as well as identifying cause-and-effect relationships, a quasi-experimental approach was adopted in this work. Nevertheless, the lack of random assignment means that it is necessary to make considerable efforts to determine the comparability of the comparison and experimental groups. The author thus tried to ensure the experimental and comparison groups were as similar as possible in the real study.

The $3 \times 3$ factorial quasi-experimental design employing a pretest-posttest comparison group, with thinking styles being a measured (i.e. naturally occurring) factor and conference structure being a manipulated factor. There are two major types of independent variables applicable to the research questions. First, there are attribute variables, which measure the preexisting characteristics of the research participants. The attribute variables in this study include thinking styles and creative thinking ability. If thinking styles are significantly related to creative thinking ability, then creative thinking ability would serve as a control variable. Second, there are manipulated variables, and these reflect a presumed cause and set up the conditions for comparison (Suter, 2006). In this study, the manipulated variables are group composition (homogeneous and heterogeneous) and conference structure (no, low and high). Moreover, the dependent variables reflect the presumed effects of the manipulation of the independent variables (Suter, 2006), and these are the measured outcomes. In this study, the dependent variables are group creativity and student perceptions of transactional distance. All of the variables are defined below.

The various types of data and collection methods are summarized in Table 2, and the processes of the instrument development along with the tests of instrument reliability and validity are described in more detail in the following subsections. 
Table: 2

Types of data collection and methods

\begin{tabular}{ll}
\hline \multicolumn{1}{c}{ Data } & \multicolumn{1}{c}{ Methods } \\
\hline Thinking Styles & $\begin{array}{l}\text { Using the Sternberg-Wagner Thinking Styles Inventory } \\
\text { Using the Abbreviated Torrance Test for Adults (ATTA) } \\
\text { Group Creativity }\end{array}$ \\
$\begin{array}{l}\text { Adapting the Creative Product Semantic Scale to develop } \\
\text { an evaluation form }\end{array}$ \\
\hline
\end{tabular}

The students' thinking styles served as the grouping factor. Originally, participants were anticipated to be divided into Executive Group, Legislative Group, Judicial Group, and Mixed Group, with the last group containing the thinking styles of the first three groups. However, there were very few participants who had the judicial thinking style in this sample.

In this study, the medium used for group conferencing was Blackboard Academic Suite, an e-Education platform that enables users to post information and assignments, and to share their academic or social experiences. It has three key areas of utility, which are as a learning system, as a community system, and as a content system. The Discussion Board enables threaded and asynchronous discussions, and this was the collaboration tool for this study. The evaluation, of group creativity in terms of the group blogs, based on the Creative Product Semantic Scale was conducted.

All the collected data were organized and compiled for analysis using SPSS Statistics 19.0. The variables of interest were analyzed with descriptive statistics, Pearson correlation tests, the t-test, analysis of variance (ANOVA) and ANCOVA tests. Reliability and validity of the instruments:The internal consistencies of the scales were estimated with the Cronbach's alpha coefficients, and exploratory factor analysis was used to support the factor structures of these instruments within this specific sample.

\section{RESULTS}

The students' thinking styles served as the grouping factor. Based on the TSI scores, every student was assigned to one of the following groups: Executive, Legislative and Mixed Students were informed that grouping was designed to facilitate online group collaboration, and thus the completion of the group assignments, which were to design two blogs. Group blogs were graded twice: once at the midterm and again at the end of the semester. All participants consented to use synchronous computer conferencing for the group discussions.

Findings Related to Gender, Thinking Styles and Creative Ability

Question 1: Are there any relationships among gender, thinking styles and creative ability?

Hypothesis 1.1: There are differences between male and female students in thinking styles.

Hypothesis 1.2: There are differences between male and female students in creative ability.

Hypothesis 1.3: There is an association between individual creative ability and thinking styles.

This study first examined whether male and female students differ in their thinking styles, as measured by the TSI and in creative ability, as measured by the ATTA. The statistical results show that the males did not differ significantly from the females on the executive $(p=.61)$ and judicial thinking styles $(p=.11)$. 
Table: 3

Means, standard deviations and $t$-tests for thinking styles between male and female students

\begin{tabular}{lllllllll} 
Thinking & \multicolumn{2}{c}{ Male $(\mathrm{n}=40)$} & \multicolumn{3}{c}{ Female $(\mathrm{n}=80)$} & \multicolumn{3}{c}{$\mathrm{t}$-test } \\
Style & $M$ & $S D$ & $M$ & $S D$ & $T(d f=133)$ & $p$ & $d$ \\
Legislative & 5.69 & .81 & 5.34 & .84 & 2.14 & .0 & .42 \\
Executive & 5.03 & .94 & 5.14 & .97 & -.51 & .61 & \\
Judicial & 4.63 & 1.09 & 4.32 & .97 & 1.6 & .11 \\
\hline
\end{tabular}

Note. $\bar{M}=$ mean. SD $=$ standard deviation. $\mathrm{df}=$ degrees of freedom. $* p<.05$.

Independent-groups $t$-tests assuming equal variances were performed to test whether there were any significant differences in thinking styles between male and female groups. Means and standard deviations of the thinking styles by gender and $t$-test results are reported in Table 4.

Table: 4

Means, standard deviations and t-test for overall creative ability between male and female students

\begin{tabular}{lllllll}
\hline & \multicolumn{2}{c}{ Male $(n=33)$} & Female & \multicolumn{2}{c}{$(\mathrm{n}=84)$} & \multicolumn{2}{c}{ t-test } \\
\cline { 2 - 7 } Measure & $M$ & SD & M & SD & T(df =125) & P \\
\hline CI & 61.7 & 6.48 & 60.29 & 6.96 & 1.02 & .31
\end{tabular}

Note. $M=$ mean. SD = standard deviation.

Before the subsets of the ATTA were compared with regard to gender differences, the results of the preliminary Levene's tests for equality of variances indicated that the variances of the two groups were not significant in the fluency $(p=.93)$, originality $(p=$ $.64)$ and elaboration $(p=.3)$ scores, whereas they were significant in the flexibility scores $(p=.003)$.

The correlation analyses between thinking styles (legislative, executive and judicial) and creative ability (the creative Index, fluency, originality, elaboration and flexibility) were undertaken to find out any possible associations. Demonstrates that there were some slight relationships between thinking styles and creative ability, although there were no significant results between any pair of variables $(p>.05)$.

Table: 5

Interco relations between thinking styles and creative ability.

\begin{tabular}{lccccc}
\hline Measure & Fluency & Originality & Elaboration & Flexibility & Creativity \\
Index & & & & & .05 \\
Legislative & -.13 & .13 & -.06 & .06 & .09 \\
Executive & & -.15 & -.06 & .01 & -.14 \\
Judicial & & & -.09 & .11 & -.003 \\
\hline
\end{tabular}

Findings Related to Individual Creative Ability and Group Creativity

Question 2: Is individual creative ability related to the overall group creative performance?

Hypothesis 2: The average of group member creative ability is correlated with the overall group creative performance.

The results reveal that the correlation coefficient for these two variables was $r=.007, p$ $=.98$, and thus there was no significant association between the average result for group member creative ability and that for overall group creative performance. 
Table: 6

Correlation between the average of group member creative and the overall group creative performance.

\begin{tabular}{llllcccc}
\hline Variable & M & SD & Skewness & Kurtosis & Kolmogorov/Sig & Pearson's (r) & p \\
\hline $\begin{array}{l}\text { Average of group } \\
\text { member creative } \\
\text { ability }\end{array}$ & 60.96 & 4.42 & .16 & .23 & $.113 / .20$ & .007 & .98 \\
$\begin{array}{l}\text { Overall group } \\
\text { creative } \\
\text { performance }\end{array}$ & 13.58 & .70 & .86 & 1.03 & $.100 / .20$ & & \\
\hline
\end{tabular}

\section{Findings Related to Factors Influencing on Group Creativity}

Question 3: Do group composition and conference structure have an effect on group creativity?

Hypothesis 3.1: There is a difference between the types of group composition with regard to group creativity.

Hypothesis 3.2: There is a difference between the levels of conference structure with regard to group creativity.

As is evident from the table 7, there were no significant differences among the legislative, executive and judicial groups $(F(2,15)=1.33, p=.29$, partial $\eta 2=.15)$ ).

Moreover, there were also no significant differences among the high-structured, lowstructured and no-structured conferences $(F(2,15)=3.56, p=.054$, partial $\eta 2=.32)$. Furthermore, no significant interaction was found between group composition and conference structure $(F(4,15)=1.62, p=.22$, partial $\eta 2=.30)$.

Table: 7

Two-way ANCOVA table for group composition and conference structure

\begin{tabular}{|c|c|c|c|c|c|c|c|}
\hline Source & $\begin{array}{l}\text { Sumof } \\
\text { Squares }\end{array}$ & df & $\begin{array}{l}\text { Mean } \\
\text { Square }\end{array}$ & $\mathbf{F}$ & Sig. & $n^{2}$ & Powerb \\
\hline Corrected model & $5.93^{a}$ & 9 & .66 & 1.53 & .22 & .48 & .48 \\
\hline Intercept & 9.37 & 1 & 9.2 & 21.8 & .000 & .59 & .99 \\
\hline Covariance & .001 & 1 & .001 & .001 & .97 & .000 & .05 \\
\hline Group composition & 1.14 & 2 & .566 & 1.33 & .29 & .15 & .23 \\
\hline Conference & 3.06 & 2 & 1.54 & 3.56 & .05 & .32 & .57 \\
\hline $\begin{array}{l}\text { Group composition } \\
\text { Conference } \\
\text { structure }\end{array}$ & 2.78 & 4 & .70 & 1.62 & .22 & .30 & .38 \\
\hline Error & 6.44 & 15 & .43 & & & & \\
\hline Total & 429.1 & 25 & & & & & \\
\hline Corrected total & 12.37 & 24 & & & & & \\
\hline
\end{tabular}

Note. $\mathrm{n} 2$ (eta squared) $=$ effect size.

$R$ squared $=.469$ (Adjusted $R$ squared $=.164)$. b. Computed using alpha $=.05$ 
Table: 8

Adjusted and unadjusted means and variability for the score of the second group blog using the score of the first group as a covariate

\begin{tabular}{cccccc}
\hline & \multicolumn{3}{c}{ Unadjusted } & \multicolumn{2}{c}{ Adjusted } \\
\cline { 2 - 6 } Group Composition & $\mathbf{N}$ & $\mathrm{M}$ & SD & M & SD \\
Legislative & 11 & 13.00 & .69 & 13.4 & .22 \\
Executive & 9 & 13.25 & .90 & 13.5 & .30 \\
Mixed & 8 & 12.9 & .64 & 13.2 & .31 \\
& & & & & \\
Conference & & & & & \\
Structure & & & & & \\
High & 9 & 13.3 & .53 & 13.4 & .26 \\
Low & 9 & 13.1 & .82 & 12.6 & .23 \\
No & 9 & 12.8 & .60 & 13.61 & .23 \\
\hline & & & & &
\end{tabular}

As shown in above, when controlling for the pre-existing group creativity, no significant effects were found for either the group composition or conference structure factor on group performance. Moreover, no significant interaction was found between these two factors.

\section{DISCUSSION}

The purpose of this study was to investigate the group creativity on thinking styles in distance education based on collaborative learning in order to enhance the creativity expressed in an online learning environment.

The results of the present work showed that the male students preferred the legislative thinking style significantly more than the female ones. This study also found that the executive thinking style was negatively correlated with originality for the female group.

Therefore, teachers should encourage students to develop different thinking styles, and provide them with opportunities to demonstrate their varied strengths by diversifying their teaching and assessment strategies, and designing a variety of group activities. Students' awareness of their own styles, as well as those of their partners, could be instrumental to the effectiveness of conflict resolution and group cohesiveness (Zhang \& Sternberg, 2009).

Some group researchers claim that by providing many different perspectives for consideration, diversity within a group can help the creative process and promote more innovative outcomes (Kurtzberg, 2005; Mamykina et al., 2002). A diverse group consists of members who are different from each other with regard to one or more characteristics (Milliken et al., 2003). However, in this study, there was no significant association between the average group member creative ability and the overall group creative performance. Furthermore, using an experimental method, no significant main effects were found for the group composition and conference structure factors on group creative performance, and no significant interaction was found between these two factors, either. That is, heterogeneous groups (mixed groups). present study, the findings reveal that overall creative ability is not related to thinking styles, as those individuals preferring a legislative style of thinking, a style related to a propensity for creativity, did not in fact have any greater creative ability. The following subsections present a number of interesting ideas about thinking styles, based on the findings of this study. 
No significant relationships between thinking styles and creative abilities were found. Sternberg's argument that ability is different from style was thus supported in this study. It did not demonstrate better creative performance than the homogeneous ones (legislative and executive groups). These findings reveal the complexity of group creative performance. Creativity is both a process and an outcome - if one cannot understand the process that created it, and then the outcome is also not well understood (Milliken et al., 2003).

In addition, group members with substantial psychological safety are more likely to feel positive about the group and its task. In contrast, group members with low psychological safety generally feel disinterested in the group and are less like to engage with it. Moreover, negative moods are associated with a high level of emotional conflict and low levels of group satisfaction, and such conflict may lead to narrow and rigid thinking, thus reducing creativity. In contrast, a positive mood may enhance participation and increase members' capacity to generate unusual and creative ideas. An additional factor that may reduce group performance is conformity, the desire for social consensus, which induces agreement without reflection and limits the ability of individuals' to think in alternative ways (Nemeth \& Nemeth-Brown, 2003). Due to fear of social sanctions or the assumption that the majority is probably correct, people in groups often agree, and this conformity harms creativity. All of these factors may affect creative processes and outcomes, and are worthy of further exploration in future research.

\section{CONCLUSION}

The greatest strengths of online collaborative learning are its flexibility, independence, cost efficiency, as well as its powerful capability to enable direct interaction and communication. It is a challenge for the teacher to create an online environment that not only emphasizes the importance of learner autonomy, but also encourages distance students to participate in noncontiguous discussions. Advances in computer conferencing systems are facilitating new opportunities for two-way communication by which groups of students can practice reflection, critical thinking and problem solving (Sumner, 2000). In addition, the potential for greater enjoyment and relaxation when taking part in computer conferencing might help learners who had previously felt frustrated to overcome their fears, and thus build a more productive and structured learning environment with a social and subject-related consensus (Nipper, 1989). Besides, the implementation of computer conferencing, an open and democratic medium, will move the locus of control from the teacher to the group and the processes generated by it, and consequently contribute to less authoritarian concepts of learning and teaching.

This research aims to uncover whether grouping and structuring are related to group creativity, and individual perceptions of transactional distance. Specifically, it examines the effects of group composition based on thinking styles and conference structure based on transactional distance theory through innovative uses of Internet technology, specifically synchronous computer conferencing. The descriptive results show that most of the respondents had positive perceptions and attitudes toward their online learning experience. In light of the findings discussed in this chapter, as well as the open-ended comments pulled from the transactional distance questionnaire, the findings of this work can assist practitioners in guiding their efforts to develop more effective collaborative activities connecting distance learners, thus reducing transactional distance in an online learning environment. They can also inspire practitioners to consider how to use synchronous computer conferencing to encourage and promote student creativity. 


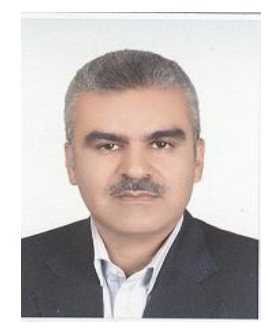

Dr. Mohammad Reza SARMADI is Faculty member of Payame Noor University in Iran. He graduated of Shahid Chamran Ahvaz with a degree in Education (PhD).

Prof. Dr. Mohammad Reza SARMADI

Payame Noor University, Faculty of Human Sciences, Department of Education and Psychology, Tehran, Iran

Phone: +9802122455419

e-Mail: sarmadi@pnu.ac.ir.

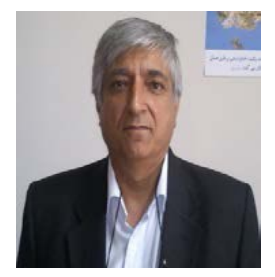

Dr. Mehran FARAJOLLAHI is Faculty member of Payame Noor University in Iran. He graduated of Shahid Chamran Ahvaz with a degree in Education (PhD).

Prof. Dr. Mehran FARAJOLLAHI

Payame Noor University, Faculty of Human Sciences

Department of Education and Psychology, Tehran, Iran

Phone: +9802122455419

e-Mail: farajollahim@yahoo.com

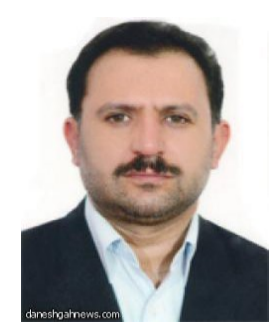

Dr. Bahman SAEIDIPOUR is Faculty member of Payame Noor University in Iran. He graduated of Shahid Chamran Ahvaz with a degree in Education (PhD).

Assoc. Prof. Dr. Bahman SAEIDIPOUR

Payame Noor University, Faculty of Human Sciences

Department of Education and Psychology, Tehran, Iran

Phone: +9802122455419

e-Mail: bahman_saeidipour@yahoo.com

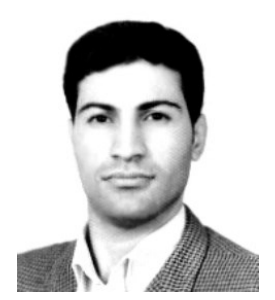

Dr. Mehrdad AHMADIFAR is Faculty member of Payame Noor University in Iran. He graduated of Shahid Chamran Ahvaz with a degree in Education (PhD).

\section{Dr. Mehrdad AHMADIFAR}

Payame Noor University, Faculty of Human Sciences

Department of Education and Psychology, Tehran, Iran

Phone: +9802122455419

e-Mmail: ahmadifar.mehr@gmail.com 


\section{REFERENCES}

Armstrong, S., \& Cools, S. (2009). Cognitive Styles and Their Relevance for Business and Management. In L.F.Zhang \& R.J.Sternberg (Eds.), Perspective on The nature of intellectual Styles (pp. 253-290). New York: Springer.

Bernardo, A., Zhang, L., \& Callueng, C. (2002). Thinking Styles and Academic Achievement among Filipino Students. Journal of Genetic Psychology, 163(2), 149.

Bonnardel, N. (2006). Créativité et conception approches cognitives et ergonomiques. Marseille : Solal.

Bonnardel, N. (2009). Activités de conception et créativité : De l'analyse des facteurs cognitifs à l'assistance aux activités de conception créatives. Le Travail Humain, 72, 5-22.

Bonnardel, N., \& Zenasni, F. (2010). The impact of technology on creativity in design: An enhancement?. Creativity \& Innovation Management, 19(2), 180-191.

de St. Aubin, E., Blahnik, J., \& Lucas, V. (2007). Ways of Thinking about Thinking Styles. PSYCCRITIQUES, 52(8).

Fjell, A., \& Walhovd, K. (2004). Thinking styles in relation to personality traits: An investigation of the Thinking Styles Inventory and NEO-PI-R. Scandinavian Journal of Psychology, 45(4), 293-300.

Haller, C., \& Courvoisier, D. (2010). Personality and thinking style in different creative domains. Psychology of Aesthetics, Creativity, and the Arts, 4(3), 149-160.

Hinsz, V. B., Tindale, R. S., \& Vollrath, D. A. (1997). The emerging conception of groups as information processors. Psychological Bulletin, 121(1), 43-64.

Kim, Y.C (2007) Group creativity: How it could be effective? The Korean Journal of Thinking \& Problem Solving, 3(1), 1-26.

Kreijns, K., Kirschner, P. A., Jochems, W., \& Van Buuren, H. (2004). Determining sociability, social space, and social presence in (a)synchronous collaborative groups. Cyber Psychology \& Behavior, 7(2), 155-172.

Kurtzberg, T. R. (2005). Feeling creative, being creative: An empirical study of diversity and creativity in teams. Creativity Research Journal, 17(1), 51-65.

Kurtzberg, T. R., \& Amabile, T. M. (2001). From Guilford to creative synergy: Opening the black box of team level creativity. Creativity Research Journal, 13(4), 285-294.

Lohman, M. C., \& Finkelstein, M. (2000). Designing groups in problem-based learning to promote problem-solving skill and self-directed-ness. Instructional Science, 28, 291307. doi: 10.1023/A:1003927228005

Mamykina, L., Candy, L., \& Edmonds, E. (2002). Collaborative creativity. Communications of the ACM Special Section on Creativity and Interface, 45(10), 96-99.

Milliken, F. J., \& Martins, L. (1996). Searching for common threads: Understanding the multiple effects of diversity in organizational group. Academy of Management Review, 21(2), 402-433.

Milliken, F. J., Bartel, C. A., \& Kurtzberg, T. R. (2003). Diversity and creativity in work groups: A dynamic perspective on the affective and cognitive processes that link diversity and performance. In P. B. Paulus \& B. A. Nijstad (Eds.), Group creativity: Innovation through collaboration (pp. 32-62). New York, NY: Oxford University Press. 
Murphy, A., \& Janeke, H. (2009). The relationship between thinking styles and emotional intelligence: an exploratory study. South African Journal of Psychology, 39(3), 357375.

Nemeth, C. \& Kwan, J.L. (1985) Learning together and alone: cooperation, competition and individualization. Englewood Cliffs, NJ: Prentice Hall.

Nemeth, C. J., \& Nemeth-Brown, B. (2003). Better than individual? The potential benefits of dissent and diversity. In P. B, Paulus \& B. A. Nijstad (Eds.), Group Creativity: Innovation through Collaboration (pp. 63-84). New York, NY: Oxford University Press.

Nemeth, C., Personnaz, M., Personnaz, B., \& Goncalo, J. (2004.) The liberating role of conflict in group creativity: A cross-cultural study. European Journal of Social Psychology, 34, 365-374.

Nipper, S. (1989). Third generation distance learning and computer conferencing. In R. Mason, \& A. Kaye (Eds), Mindweave: Communication, Computers and Distance Education (pp.63-73). Oxford, England: Pergamon Press.

Paulus, P., \& Nijstad, B. (eds.) (2003). Group creativity: Innovation through Collaboration. Oxford, England: Oxford University Press.

Sawyer. R. K. (2007). Group Genius: The Creative Power of Collaboration. New York: Basic Books.

Sawyer, R. K. (Editor) (2006). Cambridge Handbook of the Learning Sciences. New York: Cambridge University Press.

Sofo, F. (2008). Differences of degree or differences in kind? A comparative analysis of thinking styles. The International Journal of Interdisciplinary Social Sciences, 3(1), 293-301.

Sternberg, R. J. (1990). Metaphors of Mind: Conceptions of the Nature of Intelligence. New York, NY: Cambridge University Press.

Sternberg, R. J. (1997). Thinking Styles. Cambridge, England: Cambridge University Press.

Sternberg, R. J., \& Lubart, T. I. (1995). Defying the Crowd: Cultivating Creativity in a Culture of Conformity. New York, NY: Free Press.

Sternberg, R. J., \& Zhang, L. F. (2005). Styles of thinking as a basis of differentiated instruction. Theory into Practice, 44(3), 245-253.

Sujan, H. (1995). Style of thinking: A bridge between personality and cognition. Advances in Consumer Research, 22, 428-429.

Sumner, J. (2000). Serving the system: A critical history of distance education. Open Learning, $15(3), 267-85$.

Suter, W. N. (2006). Introduction to educational research: A critical thinking approach. Thousand Oaks, CA: Sage.

Tjosvold, D. (1986). Working Together to Get Things Done: Managing for Organizational Productivity, Lexington, MA: Lexington Books.

Tjosvold, D. (1988). Cooperative and competitive interdependence: Collaboration between departments to serve customers. Group \& Organizational Studies, 13(3), 274-289.

Wageman, R. (1995). Interdependence and group effectiveness. Administrative Science Quarterly, 40(1), 145-180. 
Williams, K., \& O'Reilly, C. (1998). Demography and diversity in organizations: A review of 40 years of research. In B. Staw, \& C. Cummings (Eds.), Research in Organization Behavior, 20(20), 77-140. Stamford, CT: JAI Press.

Woo, S.H, Lee, H.J \& Kim, J.W (2009) A method of composing an effictive design cooperative learning group-elementary school students in the early grades, Journal of Korean Society of Design Science, 22(4). 93-108.

Woo, S.H. (2010) Design cooperative learning for promoting creativity on early elementary grades: A method for group composition. Ph.D. Thesis, Yeon-sae university.

Yang, S., \& Lin, W. (2004). The Relationship Among Creative, Critical Thinking and Thinking Styles in Taiwan High School Students. Journal of Instructional Psychology, 31(1), 33-45.

Zhang, L. (2003). Are parents and children's thinking styles related. Psychological Reports, 93(2), 617-630.

Zhang, L. (2010). Do thinking styles contribute to metacognition beyond self-rated abilities? Educational Psychology, 30(4), 481-494.

Zhang, L. (2011). The developing field of intellectual styles: Four recent endeavours. Learning \& Individual Differences, 21(3), 311-318.

Zhang, L., \& Sternberg, R. (2002). Thinking styles and teacher characteristics. International journal Psychology, 37(1), 3-12.

Zhang, L., \& Sternberg, R. (2005). A threefold model of intellectual styles. Educational Psychology Review, 17(1), 1-53.

Zhang, L., \& Sternberg, R. (2006). The Nature of Intellectual Styles. New Jersey: Lawrence Erlbaum.

Zhang, L. F., \& Sternberg, R. J. (Eds.) (2009). Perspectives on the Nature of Intellectual Styles. New York, NY: Springer Publishing Company. 